\title{
Copper and clioquinol treatment in young APP transgenic and wildtype mice: effects on life expectancy, body weight and metal-ion levels
}

\author{
Stephanie Schäfer • Frank-Gerald Pajonk • \\ Gerd Multhaup - Thomas A. Bayer
}

Published online: 2 March 2007

(C) Springer-Verlag 2007

\section{Erratum to: Journal of Molecular Medicine}

DOI 10.1007/s00109-006-0140-7

The above mentioned article (doi: 10.1007/s00109-0060140-7) contained unreferenced text in the discussion that requires specification: a sentence in the last paragraph of the discussion reads: "A phase III study that used [clioquinol] $\mathrm{CQ}$ for the treatment of $\mathrm{AD}$ patients has been dropped because of the intrinsic toxicity of the chelator."

The website of Prana Biotechnology, which funded the PLACQUE trial, states that the reasons for not advancing with the phase II/III study of clioquinol (5-Chloro-8-hydroxy-7-iodoquinoline) was an impurity in the trial batch. This impurity, di-iodohydroxyquinoline, was suspected to have genotoxic potential and PRANA chose not to commence the trial rather than attempt to purify or resynthesize the batch. Further details are given at http://www.pranabio.com/downloads/ PBT_AR_2005.pdf)

The online version of the original article can be found at: $h t t p: / / d x$. doi.org/10.1007/s00109-006-0140-7.

S. Schäfer · F.-G. Pajonk · T. A. Bayer $(\bowtie)$

Department of Psychiatry, Division of Neurobiology,

Saarland University,

Homburg, Germany

e-mail: thomas.bayer@uniklinik-saarland.de

G. Multhaup

Institute for Biochemistry, Free University of Berlin,

Berlin, Germany 